\title{
Diagnóstico del eje transinsular de transportes en el contexto de la integración territorial de Canarias
}

\author{
Diagnosis of the transinsular transportation axis \\ in the context of the Canary Islands' territorial integration \\ José Ángel Hernández Luis \\ jose.hernandez@ulpgc.es \\ Departamento de Geografía \\ Universidad de Las Palmas de Gran Canaria (España)
}

\section{Resumen}

El objetivo central de este trabajo es la realización de un diagnóstico -al igual que la viabilidad-, del denominado Eje Transinsular de Infraestructuras y Transportes, promovido por el Gobierno de Canarias, con el fin de paliar la fragmentación territorial de las Islas. Se aborda el caso de la intermodalidad entre el transporte marítimo y terrestre desde diferentes puntos de vista (accesibilidad horaria, económica, etc.), demostrando el actual déficit que existe desde el punto de vista de la cohesión territorial. Se estudia por último cómo hacer más sostenible dicha integración territorial.

Palabras clave: Eje Transinsular de Transportes; transporte intermodal; integración territorial; sostenibilidad; Islas Canarias.

\footnotetext{
Abstract

The main aim of this paper is developing a diagnostic and viability of Transinsular Axis of Infrastructure and Transport, promoted by the Canary Islands Government, in order to lessen the territorial fragmentation of the Islands. We study the case of intermodality between sea and land 
transport from different points of view (time accessibility, economic...), and we show with it the current deficit that exists from the point of view of territorial cohesion. Finally we show how to make more sustainable territorial integration of the islands.

Key words: Transinsular Transportation Axis; intermodal transport; spatial integration; sustainability; Canary Islands.

\section{Introducción}

Este trabajo se enmarca dentro de un proyecto en desarrollo con el objeto de analizar la relación entre los puertos y el desarrollo socioeconómico en varios territorios, entre ellos Canarias. Se analiza aquí la políica impulsada por el Gobierno de Canarias y conocida como el Eje Transinsular de Transportes - como subsidiario de las Redes Transeuropeas de Transporte-, con el objeto de estimular la cohesión territorial de las Islas que emana de su fragmentación y lejanía.

Para realizar este cometido, seguimos un procedimiento metodológico en el que realizamos en primer lugar un diagnóstico del transporte intermodal entre islas entre la carretera y la vía marítima (demanda actual, situación de los puertos y carreteras, accesibilidad horaria y económica, etc.), al tiempo que elaboramos un balance ambiental de la mejora de la accesibilidad marítima, como preconiza en especial el citado Eje Transinsular de Transportes, para finalizar con un planteamiento de desarrollo sostenible a modo de conclusión.

Todo ello tiene como objetivo la tipificación de los principales problemas de accesibilidad detectados (mejora de la planificación horaria, una política tarifaria escasamente incentivadora, la situación encorsetada de algunas infraestructuras portuarias y de carreteras, etc.). Para ello, aportamos las soluciones pertinentes en cada caso $y$, como decimos, en un contexto de sostenibilidad, en el que el desarrollo económico y social de Canarias deriva en gran medida de aminorar la fragmentación territorial de las Islas a través de la mejora de la accesibilidad interinsular, particularmente la marítima - terrestre como se aborda en este trabajo.

\section{Estado del arte}

Partiendo de la base de que el transporte marítimo para los sistemas insulares es absolutamente fundamental para su desarrollo socioeconómico, pues con ello se logra paliar, en cierto modo, la discontinuidad territorial, al igual que la lejanía, diversa bibliografía ha abordado en los últimos años esta problemática. En especial, desde el punto de vista del transporte marítimo, y entre otras, habría que destacar varias aportaciones: (Brookfield, 1980; Hernández Luis, 1994; Coccossis \& Nijkamp, 1995; Eurisles, 1996; Rutz \& Coull, 1996; Gobierno de Canarias, 1998; Cross \& Nutley, 1999; Hoyle, 1999; Button \& Taylor, 2000; Bowen, 2000; Fundación Tomillo, 2001; Guillaumin, 2001; Hernández Luis, 2002; Tzannatos, 2005; Chlomoudis, 2007; Kapros, 2007; Yamaguchi, 
2007; Rigas, 2009; Tsekeris, 2009; Hazledine \& Collins, 2011). Como decimos, todas estas aportaciones tienen en común -y como eje conductor-, la incidencia que tiene la accesibilidad para el desarrollo socioeconómico, sobre todo para los espacios insulares y, dentro de éstos, en especial aquéllos que presentan mayores problemas de conectividad.

Por su parte, la Red Transeuropea del Transporte, ha generado cientos de trabajos desde muy diversas perspectivas (desarrollo económico y social, ambiental, desequilibrios territoriales, etc.), particularmente desde mediados los años noventa. La propia Unión Europea argumenta que dicha Red es fundamental para la economía y que las previsiones auguran un crecimiento para 2050 del 80 y del 50 por ciento respectivamente del tráfico de mercancías y pasajeros, por lo que aquellos territorios con déficit de conectividad no van a prosperar (Comisión Europea, 2011), de ahí que se incida en los denominados espacios ultraperiféricos o también los sistemas insulares.

En esta filosofía se inserta el Eje Transinsular de Transportes de Canarias, como subsidiario de la mentada Red Transeuropea del Transporte. En particular, dentro de la citada Red Transinsular, en los últimos años han adquirido importancia los estudios que abordan las temáticas de la integración o cohesión territorial que deriva de la mejora de la accesibilidad y, en concreto, cada vez más aportaciones hacen hincapié en los tiempos de viaje y sus consecuencias para la accesibilidad de las personas y mercancías, cuestión que es uno de los factores más importantes para el éxito del susodicho Eje Transinsular de Transportes. Desde este punto de vista, habría que destacar, entre otros trabajos, los siguientes: (Hernández Luis, 2002; Liu \& Zhu, 2004; Yamaguchi, 2007; Jain \& Lions, 2008; Rigas, 2009; Chang, 2010; Lei \& Church, 2010; Benenson, 2011; Grubesic \& Fangwu, 2013; Price \& Matthews, 2013; Chowdhury, 2015).

Más en concreto, otros autores se han detenido en la problemática de la intermodalidad entre el transporte marítimo y el terrestre, en aras de la mejora de la conectividad (Knowles, 2006; Xie, 2009; Ferrari, 2011; Pitsiava-Latinopoulou, 2012; Escudero, 2013; Reis, 2014), y de forma específica para el caso de las islas esta temática ha sido desarrollada por otros autores (Rutz \& Coull, 1996; Hernández Luis, 2002; Rigas, 2009; Morfoulaki, 2012).

Del mismo modo, y de manera más concreta aún, algunos trabajos se han centrado en analizar la incidencia que ha tenido la accesibilidad del transporte público a determinados lugares funcionales, como pueden ser los comercios o las administraciones, condicionado sobre todo por los horarios de apertura de éstos y su compatibilidad con los horarios del transporte público marítimo, terrestre y aéreo (Nutley, 1983; Rodríguez, 1989; López Lara, 1990; Niemeier, 1997; Nutley, 1998; Cross \& Nutley, 1999; Hernández Luis, 2000; Nutley, 2005; Farrington, 2007; Yamaguchi, 2007; Neutens, 2012). Ello, conjuntamente con otras aportaciones que se han centrado en los horarios del transporte como herramienta para evaluar la accesibilidad temporal de la que disponen las unidades de tráfico (Kaakai, 2006; Guihaire, 2010; Robenek, 2016), sientan las bases de las líneas 
metodológicas del presente artículo, donde el análisis de la accesibilidad horaria, aunque también económica y el diagnóstico de las infraestructuras del transporte, se convierten en la columna vertebral, tomando como base sobre todo los trabajos mencionados.

\section{Breve marco territorial de Canarias}

Las Islas Canarias han aumentado su población en casi un 120 por ciento en los últimos 55 años, hasta llegar a los 2,1 millones de habitantes en 2015 (algo más de 2,3 si se incluye el flujo turístico). Este hecho, conjuntamente con el trasvase de población activa desde el sector primario al terciario y el aumento de actividad económica que ello ha conllevado, ha favorecido un incremento extraordinario de la movilidad interinsular, sobre todo a través del medio marítimo.

La dependencia económica que las Islas tienen de la actividad turística es muy alta, pues aunque no se puede decir que toda la actividad terciaria dependa de dicha actividad, sí que es cierto que el turismo no solo repercute en el terciario, sino también en otros sectores. De cualquier modo, la actividad terciaria genera en la actualidad un $78 \%$ del Valor Añadido Bruto y, sin duda, ha contribuido al incremento de la renta per capita, favoreciendo ello el aumento de la movilidad (Dijst, 2000; Tindemans, 2005), en este caso de los residentes en las Islas.

Tabla 1. Principales macromagnitudes de las Islas Canarias entre 1960 y 2015

\begin{tabular}{|c|c|c|c|c|c|}
\hline \multirow[b]{2}{*}{ Años } & \multirow[b]{2}{*}{ Población } & \multirow[b]{2}{*}{$\begin{array}{c}\text { Turistas } \\
\text { extranjeros }\end{array}$} & \multicolumn{3}{|c|}{ Activos ocupados } \\
\hline & & & Sector $1^{\circ}$ & Sector $2^{\circ}$ & Sector $3^{\circ}$ \\
\hline 1960 & 966177 & 69000 & 185025 & 47798 & 113010 \\
\hline 1970 & 1125442 & 821000 & 127716 & 90174 & 192205 \\
\hline 1981 & 1367669 & 2521500 & 87275 & 93785 & 276583 \\
\hline 1991 & 1493784 & 5495000 & 44133 & 96753 & 356168 \\
\hline 2001 & 1781366 & 10137202 & 39160 & 109661 & 488370 \\
\hline 2011 & 2082655 & 10176968 & 21520 & 89900 & 657260 \\
\hline 2015 & 2100306 & 11765227 & 28040 & 92030 & 773580 \\
\hline Variación 1960-2015 & $117,40 \%$ & $16951,10 \%$ & $-84,90 \%$ & $92,50 \%$ & $584,50 \%$ \\
\hline
\end{tabular}

Fuente: elaboración propia a partir del Instituto Canario de Estadística (2017)

y Renta Nacional de España y su distribución provincial (BBVA, 2016)

De cualquier manera, la distribución de la población y de la riqueza dentro del Archipiélago varía considerablemente. En ello inciden multitud de parámetros: desde causas históricas hasta condicionantes del relieve, desarrollo de las infraestructuras portuarias, etc. Esta desigual distribución tiene consecuencias notables en el transporte exterior, pues por ejemplo la demanda de servicios marítimos es bastante dispar dependiendo de las rutas. Así pues, el hinterland de cada espacio insular va a condicionar la demanda de transporte marítimo, si bien es verdad que cada 
isla necesita de unos niveles mínimos de servicio que, en principio, por su volumen demográfico y económico, no se justificarían.

Tabla 2. Principales características insulares de las Islas Canarias en 2015*

\begin{tabular}{|l|c|c|c|}
\hline Islas & Población & Turistas extranjeros & $\begin{array}{c}\text { Valor Añadido Bruto de } \\
\text { todos los sectores } \\
\text { económicos (\%) }\end{array}$ \\
\hline Tenerife & 888184 & 4207403 & 42 \\
\hline Gran Canaria & 847830 & 3271941 & 42 \\
\hline Lanzarote & 143209 & 2193291 & 6 \\
\hline Fuerteventura & 107367 & 1966634 & 4 \\
\hline La Palma & 82346 & 125958 & 0.5 \\
\hline La Gomera & 20783 & - & 0.5 \\
\hline El Hierro & 10587 & - & 100 \\
\hline Total & 2100306 & 11765227 & 5 \\
\hline
\end{tabular}

Leyenda: * Solo se incluyen los turistas entrados por vía aérea. En 2015, las llegadas de turistas en cruceros a Canarias se elevaron a 2185469 .

Fuente: elaboración propia a partir del Instituto Canario de Estadística (2017)

Como se deduce de la tabla 2, los desequilibrios entre islas son notables, hecho que también incide en una dispar demanda marítima. En efecto, Tenerife y Gran Canaria concentran el 83 por ciento de la población. El restante 17 por ciento también se distribuye desigualmente, pues si algo más del 15 por ciento de la población se localiza en las islas de Lanzarote, La Palma y Fuerteventura, el restante porcentaje, esto es, ni siquiera el dos por ciento, se reparte entre La Gomera y El Hierro. El Valor Añadido Bruto difiere muy poco de estos valores.

\section{Análisis de la reciente evolución del tráfico marítimo entre las islas Canarias}

En la actualidad existe una docena de líneas que operan el tráfico marítimo regular de pasaje y carga entre Canarias, si bien son cuatro rutas las que superan los 500000 viajeros al año y que, por orden de importancia serían: Los Cristianos-San Sebastián de La Gomera; Playa BlancaCorralejo; Santa Cruz de Tenerife-Agaete; y Las Palmas de Gran Canaria-Morro Jable. Los operadores principales son Naviera Armas y Fred. Olsen, con frecuencias entre todas las islas, excepto la última que no opera actualmente con El Hierro. También existen otros dos operadores que realizan la travesía corta entre Órzola y La Graciosa (Líneas Marítimas Romero y Biosfera Express), mientras que Trasmediterránea opera en cinco islas pero con una sola frecuencia semanal con la embarcación que realiza el servicio con Cádiz. Además, cada naviera se ha especializado en una determinada tecnología operativa con sus ventajas y desventajas, como por ejemplo Fred. Olsen con los fast ferry, muy efectivos en cuanto a la reducción de los tiempos de viaje, si bien 
bastante vulnerable debido a su alto consumo de combustible y el precio de este producto en los mercados internacionales.

Figura 1. Líneas de pasaje marítimo regular en Canarias a 31 de diciembre de 2016

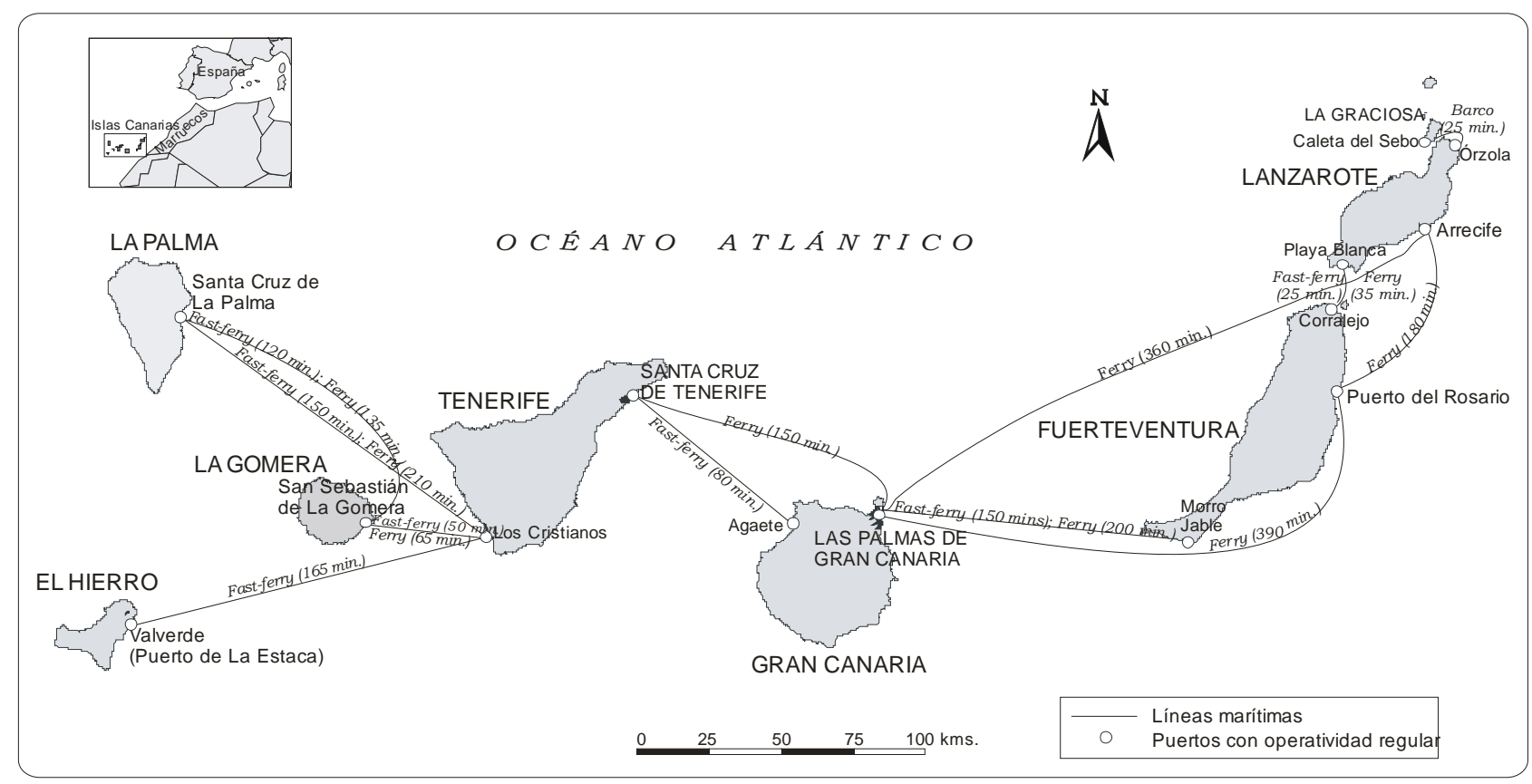

Fuente: elaboración propia a partir de los Horarios e itinerarios oficiales de las navieras (Naviera Armas, Fred. Olsen, Trasmediterránea, Líneas Marítimas Romero y Biosfera Espress, 2016)

Pues bien, la evolución del tráfico marítimo entre islas ha seguido una dinámica ascendente en los últimos años a pesar de la crisis económica. En concreto, el incremento del movimiento de pasajeros ha aumentado un $23 \%$ entre 2010 y 2015. Pero esta cifra que, en principio, podría achacarse al alza del turismo en las Islas, pues en algunos puertos es muy importante el movimiento de turistas extranjeros a otras islas en un viaje de ida y vuelta en una misma jornada, como por ejemplo Corralejo, Playa Blanca, Órzola o Los Cristianos, no parece justificarse por este motivo y en su integridad dicho aumento, pues el tráfico de vehículos por vía marítima ha aumentado más aún, hasta sobrepasar el $40 \%$. Este hecho demuestra que son sobre todo los residentes en Canarias los que más han contribuido a la mencionada variación al alza. En efecto, los turistas extranjeros que embarcan su vehículo son muy escasos, ya que la mayor parte de casas de alquiler de vehículos penaliza el transporte de éstos a otras islas, mientras que cada vez más los residentes viajan por vía marítima con sus vehículos. Por tanto, es una demanda cautiva que ha pasado de 4,7 pasajeros por vehículo en 2010, a 4 en 2015, siendo por lo general dicho grado de cautividad mayor conforme aumenta la distancia operativa, pues para estas rutas la competitividad con el transporte aéreo crece considerablemente. 
Tabla 3. Evolución del tráfico regular de viajeros y vehículos tipo "turismo" en régimen de pasaje en sistema ro-ro en Canarias entre 2010 y 2015

\begin{tabular}{|l|c|c|c|c|c|c|}
\cline { 2 - 7 } \multicolumn{1}{c|}{} & \multicolumn{3}{c|}{ Pasajeros regulares } & \multicolumn{2}{c|}{ Vehículos en roll-on / roll-off } \\
\hline Puertos del Estado & 2010 & 2015 & Aumento \% & 2010 & 2015 & Aumento \% \\
\hline Arrecife & 72197 & 124816 & 72,88 & 18276 & 44372 & 142,79 \\
\hline Puerto del Rosario & 12537 & 61087 & 387,25 & 2723 & 17278 & 534,52 \\
\hline Puerto de La Luz & 789391 & 1099482 & 39,28 & 203706 & 357079 & 75,29 \\
\hline S/C de Tenerife & 1125204 & 1286006 & 14,29 & 271637 & 385286 & 41,84 \\
\hline Los Cristianos & 1516944 & 1589339 & 4,77 & 259653 & 327366 & 26,08 \\
\hline S. S. de La Gomera & 1112863 & 1153797 & 3,68 & 187353 & 215017 & 14,77 \\
\hline S/C de La Palma & 202389 & 244613 & 20,86 & 58110 & 85716 & 47,51 \\
\hline Valverde & 100752 & 108568 & 7,76 & 27542 & 40346 & 46,49 \\
\hline Subtotal & 4932277 & 5667708 & 14,91 & 1029000 & 1472460 & 43,10 \\
\hline Puertos canarios & \multicolumn{7}{|c|}{} \\
\hline Caleta del Sebo & 207383 & 325199 & 56,81 & - & - & - \\
\hline Puerto de Orzola & 207383 & 325199 & 56,81 & - & - & - \\
\hline Playa Blanca & 732666 & 1029651 & 40,53 & 188794 & 225468 & 19,43 \\
\hline Corralejo & 732666 & 1029651 & 40,53 & 188794 & 225468 & 19,43 \\
\hline Gran Tarajal* & 10152 & - & - & 8891 & & - \\
\hline Morro Jable & 253872 & 518875 & 104,38 & 85294 & 199075 & 133,40 \\
\hline Agaete & 661881 & 833687 & 25,96 & 183594 & 289017 & 57,42 \\
\hline Playa Santiago* & 53589 & - & - & - & - & - \\
\hline Valle Gran Rey* & 99641 & - & - & - & - & - \\
\hline Subtotal & 2959233 & 4062262 & 37,27 & 655367 & 939028 & 43,28 \\
\hline TOTAL & 7891510 & 9729970 & 23,30 & 1684367 & 2411488 & 43,17 \\
\hline
\end{tabular}

Leyenda: * Estos puertos registraron actividad comercial regular en 2010, dejando de operar las líneas respectivas en el verano de 2012

Fuente: elaboración propia a partir de las Memorias Anuales de Puertos del Estado y de las Memorias Anuales de Puertos canarios (2010 y 2015)

Figura 2. Pasaje marítimo regular en líneas directas en Canarias en 2015

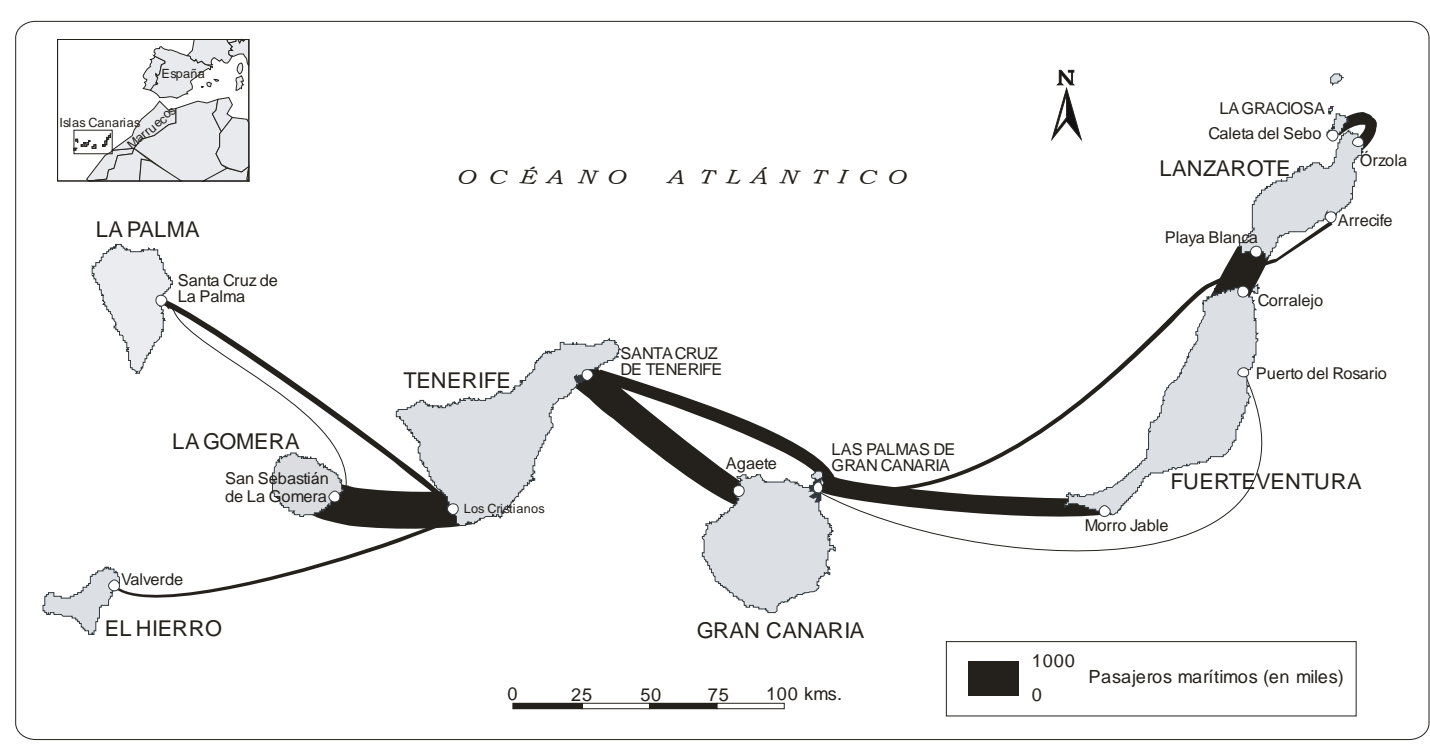

Fuente: elaboración propia a partir de las Memorias Anuales de Puertos del Estado y de las Memorias Anuales de Puertos canarios (2010 y 2015) 
Por tanto, la variación al alza del movimiento portuario interinsular, justifica una mejora de la accesibilidad entre islas, en la actualidad bastante restringida como veremos debido a algunas limitaciones en materia de horarios, tarifas, etc.

Si bien es verdad que debido a la capacidad de los buques que operan entre islas, el factor de ocupación es bajo, toda esta demanda añadida ha podido canalizarse perfectamente con las frecuencias ya existentes, pues estas últimas entre ambas fechas solo han aumentado un $10 \%$, llegando a decrementos incluso en algunos puertos de alta demanda como por ejemplo en Los Cristianos y San Sebastián de La Gomera.

\section{Tabla 4. Evolución de las frecuencias marítimas regulares de pasaje interinsular por semana según puertos (entradas más salidas) entre 2010 y 2017}

\begin{tabular}{|l|c|c|c|}
\hline Puertos del Estado & Invierno 2009-2010 & Invierno 2016-2017 & Incremento \% \\
\hline Arrecife (Lanzarote) & 16 & 16 & 0,00 \\
\hline Puerto del Rosario (Fuerteventura) & 8 & 12 & 50,00 \\
\hline Puerto de La Luz (Gran Canaria) & 76 & 108 & 42,11 \\
\hline S/C de Tenerife (Tenerife) & 133 & 122 & $-8,27$ \\
\hline Los Cristianos (Tenerife) & 122 & 104 & $-14,75$ \\
\hline S. S. de La Gomera (La Gomera) & 165 & 116 & $-29,70$ \\
\hline S/C de La Palma (La Palma) & 30 & 28 & $-6,67$ \\
\hline Valverde (El Hierro) & 16 & 12 & $-25,00$ \\
\hline Subtotal & 566 & 518 & $-8,48$ \\
\hline Puertos canarios & \multicolumn{3}{|l|}{} \\
\hline Caleta del Sebo (La Graciosa) & 168 & 224 & 33,33 \\
\hline Puerto de Órzola (Lanzarote) & 168 & 224 & 33,33 \\
\hline Playa Blanca (Lanzarote) & 184 & 232 & 26,09 \\
\hline Corralejo (Fuerteventura) & 184 & 232 & 26,09 \\
\hline Gran Tarajal (Fuerteventura) ${ }^{*}$ & 4 & - & - \\
\hline Morro Jable (Fuerteventura) & 14 & 42 & 200,00 \\
\hline Agaete (Gran Canaria) & 76 & 76 & 0,00 \\
Playa Santiago (La Gomera) ${ }^{\star}$ & 21 & - & - \\
Valle Gran Rey (La Gomera) $^{*}$ & 21 & - & - \\
\hline Subtotal & 840 & 1.030 & 10,62 \\
\hline TOTAL & 1.406 & 1.548 & 10,10 \\
\hline
\end{tabular}

Leyenda: * Estos puertos registraron actividad comercial regular en 2010, dejando de operar las líneas respectivas en el verano de 2012

Fuente: elaboración propia a partir de Biosfera Express (2010 y 2017), Fred. Olsen (2010 y 2017), Líneas Marítimas Romero (2010 y 2017), Naviera Armas (2010 y 2017) y Trasmediterránea (2010 y 2017)

Solo cabría señalar el aumento de las frecuencias en Morro Jable entre ambas fechas debido a que se incorporan los servicios de Fred. Olsen, siendo un puerto que deja de estar operado solo por una naviera, al igual que aparece una nueva naviera en Playa Blanca y Corralejo. Pero en definitiva, la operatividad de las frecuencias según puertos es muy dispar, siendo bastante mayor en los que sirven de soporte para el Eje Transinsular de Transportes. 


\section{La filosofía del Eje Transinsular de Infraestructuras y Transportes de Canarias}

El Eje Transinsular de Transportes o la Red Transcanaria de Transportes como también se le denomina, es una nueva concepción del transporte entre las Islas Canarias basada en el cambio modal de transportes y, en especial, el terrestre con el marítimo de corta distancia, además del aéreo. De esta manera, se potencia el que una mercancía rodada partiendo desde cualquier isla pueda llegar a otra en la misma jornada, incluyendo además el retorno a la isla de origen de la cabeza tractora, camión, furgoneta, etc., que desplazó la mercancía. No obstante, ello queda condicionado a los enganches de los horarios marítimos que se producen entre la isla anterior y la siguiente, siendo mayor el riesgo de que ni siquiera la ida se pueda realizar en una misma jornada conforme los tiempos de tránsito en otras islas van aumentando, por ejemplo entre Lanzarote y La Palma vía Fuerteventura, Gran Canaria y Tenerife.

Como decimos, el Eje Transinsular de Transportes es un nuevo concepto de movilidad cimentado en la mejora de la accesibilidad entre islas, además de en el interior de cada una de ellas. Su objetivo principal es facilitar la cohesión territorial, social y económica de Canarias a través de la intermodalidad entre los transportes terrestres, marítimos y aéreos, teniendo como soporte tanto la mejora de las infraestructuras, como de los medios de transporte. ${ }^{1}$ Es óbice que en este apartado tienen especial incidencia los puertos y aeropuertos, pero especialmente los primeros como reconoce el Gobierno de Canarias al argumentar que son los "elementos básicos del abastecimiento insular y de transporte de mercancía" y, en suma, "constituyen elementos imprescindibles para la articulación territorial del Archipiélago, a través del Eje Transinsular de Transportes" (Gobierno de Canarias, 2002).

La concepción del transporte intermodal que venimos argumentando, en el que algunas cuestiones como el factor tiempo y la disponibilidad de cupo son fundamentales para una óptima accesibilidad, tiene sólidas raíces en la Red Transeuropea de Transportes e incluso, el Eje Transinsular de Transportes se propone enlazar con dicha red tanto a través del transporte marítimo como del aéreo. De hecho, la Decisión 1692/96/CE del Parlamento Europeo y del Consejo, de

1 El Plan Director de Infraestructuras de Canarias (1998), en la parte III, análisis sectoriales Tomo I, p. 67, señala como objetivos principales del Eje Transinsular de Transportes una política que garantice al menos los siguientes apartados:

1) unos mínimos de movilidad sin producir efectos nocivos sobre el medio ambiente; 2) Defina y desarrolle una red interinsular que integre los modos marítimos, aéreos y terrestres; y 3) Interconecte la red antes descrita con los sistemas de transportes continentales.

A su vez, la Ley 13/2007, de 17 de mayo, de Ordenación del Transporte por Carretera de Canarias (BOE, nº 143, de 15 de junio de 2007, artículo 33, dice que el Eje Transinsular debe garantizar

el transporte de personas y mercancías al menor tiempo y coste posibles y con la mayor frecuencia, integrando los horarios, frecuencias y tecnología a disposición del usuario de los modos terrestres, marítimos y aéreos. 
23 de Julio de 1996, sobre la Red Transeuropea de Transportes, definía con carácter indicativo aquellos proyectos que, por su trascendencia, debían ser considerados de especial importancia por la Unión Europea. ${ }^{2}$ Entre dichos proyectos la Decisión resalta los relacionados con el transporte multimodal. En concreto, el Eje Transinsular de Transportes encaja dentro del artículo 18 de dicha Decisión, pues da la posibilidad de que los estados miembros aporten sus propuestas de redes integradas entre sí y con el resto de la Unión.

Como decimos, el Eje Transinsular de Transportes se apoya tanto en las infraestructuras como en el transporte en sí. Particularmente en materia de infraestructuras, los Convenios de colaboración entre el Ministerio de Fomento y el Gobierno de Canarias en materia de carreteras, que datan de 1997 y de 2006, este último con finalización teórica en 2017, han programado una serie de obras, con preferencia en el Eje Transinsular de Transportes que, sin duda, han contribuido a mejorar de forma ostensible la accesibilidad dentro de las propias islas, pero también con el exterior.

Como decimos, es muy cierto que son fundamentales las infraestructuras para el Eje Transinsular de Transportes, pero también lo es la conectividad de los medios de transporte. En este sentido, un factor clave es la coordinación de horarios cuando se hace uso de las travesías cortas, de tal modo que se permita el flujo continuo de pasajeros y mercancías entre islas. Otro aspecto importante son los tiempos de travesía y terrestres. Si bien es verdad que éstos pueden oscilar ligeramente en función del estado del mar y del tráfico viario en cada hora, lo cierto es que para que se cumpla la filosofía central del Eje Transinsular de Transportes, se hace necesaria la utilización de fast ferrys en el mar y la mejora de las condiciones viales, de tal manera que se alcancen velocidades medias aceptables dentro de los parámetros de seguridad.

Si bien es cierto que el Eje Transinsular de Transportes se marca también como objetivos el desarrollo del billete único puerta-puerta, el fomento de nuevas tecnologías aplicadas al transporte, la potenciación y optimización de los transportes públicos existentes y el desarrollo de nuevos medios de transporte como los trenes de las islas de Tenerife y Gran Canaria, la clave en la actualidad se centra sobre todo en el grado de accesibilidad marítima que puedan aportar las navieras, así como la mejora de las carreteras, pues como veremos, no puede justificarse un Eje Transinsular cuando una mercancía rodada cuenta incluso con más de seis horas de espera en un puerto de tránsito.

2 La filosofía de la Red Transeuropea de Transportes (RTE) tiene sus raíces a finales de los años ochenta en la propuesta de creación de un gran Mercado Único, pues se pensaba que para potenciar la circulación de mercancías, personas y servicios, se hacía necesaria la mejora de la accesibilidad en el territorio. En este sentido, el Tratado de la Unión Europea recoge, en el capítulo XV, artículos 154, 155 y 156, la necesidad de que la Unión desarrolle la citada Red en aras de fomentar el mercado interior, así como la integración socioeconómica de las distintas regiones. De hecho, el Libro Blanco del Transporte de la Unión Europea argumenta que "conviene mantener el apoyo a la Red Transeuropea, ya que representa un elemento importante de la competitividad europea y permite conectar mejor las regiones periféricas a los mercados centrales de la Unión Europea" (Comisión Europea, 2001). 
Figura 3. Estado de las autopistas marítimas

dentro del Eje Transinsular de Transporte canario a 31 de diciembre de 2016

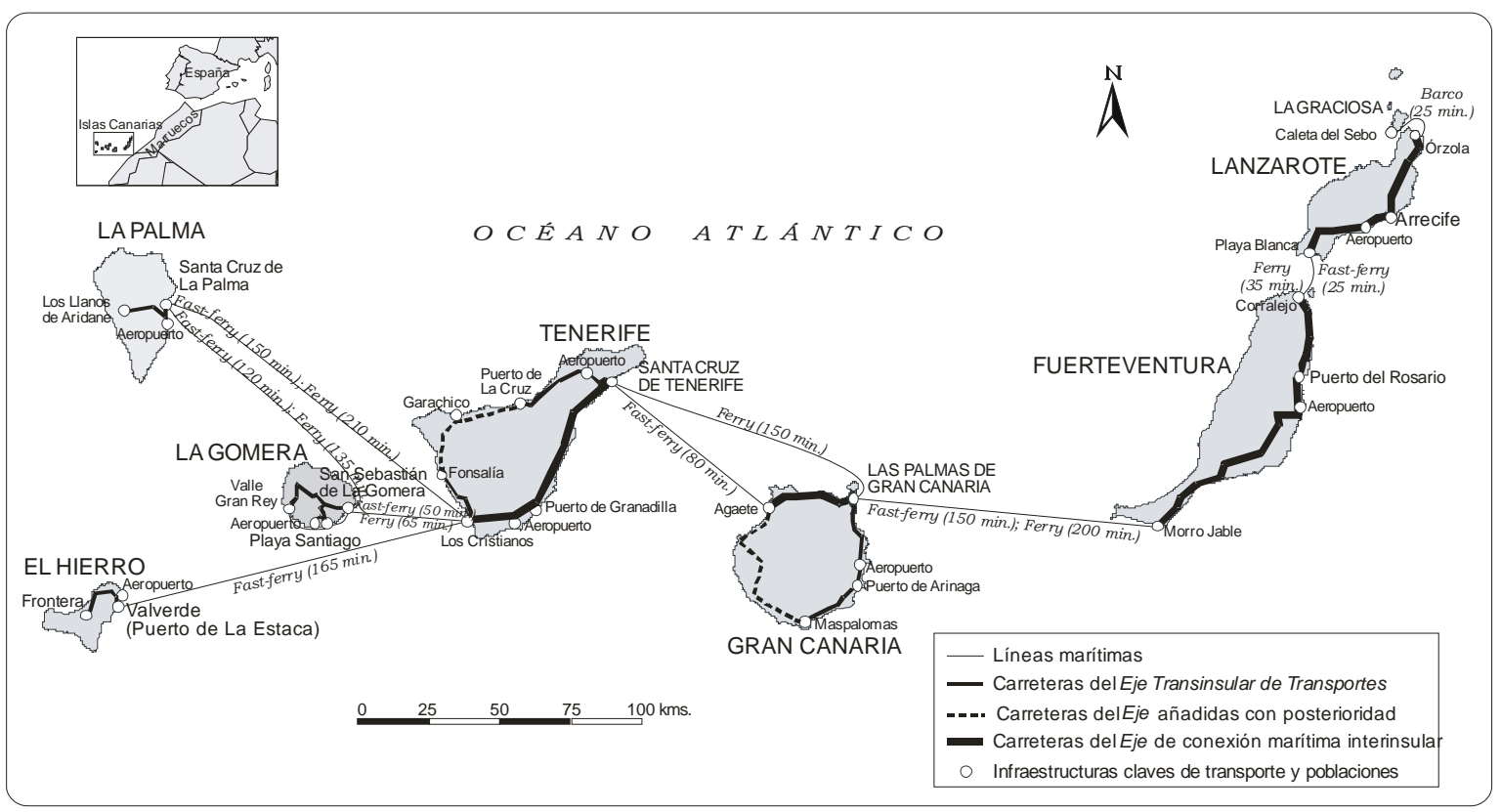

Fuente: elaboración propia a partir

del Plan Director de Infraestructuras de Canarias y Navieras (2016)

Por último y en la línea de lo comentado más arriba, es necesario conectar el Eje Transinsular de Transportes con las Redes Transeuropeas de Transportes, a la vez que con los espacios geográficos más inmediatos y que en principio podrían ser tanto la costa occidental africana, como el resto de archipiélagos macaronésicos, hecho que en un primer momento se podría potenciar con el importante flujo turístico que por ejemplo recibe la isla de Madeira. Por tanto, el gran reto es articular la red interior de transportes (la terrestre), con la exterior (marítima y aérea), especialmente deficiente en las islas periféricas. De cualquier manera, una red de transporte integrada va más allá de la simple conexión física, pues es necesario evaluar los costes de los desplazamientos, las frecuencias, los horarios, la disponibilidad de asientos o metros lineales de carga, a la vez que el tiempo global de transporte, es decir, la accesibilidad global del sistema puerta-puerta. En estos parámetros radica gran parte de la pretendida cohesión territorial que emana de la filosofía central de la Red Transeuropea de Transportes y de su subsidiario, el Eje Transinsular de Transportes canario.

\section{Estado actual del Eje Transinsular de Infraestructuras y Transportes}

En este apartado realizamos un diagnóstico de la situación del Eje Transinsular de Infraestructuras y Transportes, en tanto que éste es el que nos va a marcar el grado de integración territorial que se pretende con esta política de transportes. Así pues, tomamos la situación de las infraestructuras portuarias y de carreteras que son el soporte de la conexión de dicho Eje Transinsular, haciendo 
alusión también a sus perspectivas futuras, para luego analizar las actuales conexiones marítimas desde un punto de vista horario y tarifario.

\subsection{Situación de los puertos del Eje Transinsular}

Los puertos son una pieza clave para el desarrollo de las Islas, aunque muy dependientes de la accesibilidad que hasta ellos les proporcione la red viaria. Por tanto, es indispensable que le dediquemos un apartado específico a las infraestructuras portuarias, abordando las características básicas de éstas, así como sus principales fortalezas y debilidades.

Pues bien, la docena de puertos que sirven de base para la potenciación del Eje Transinsular, presentan características bien distintas aunque, no obstante, han posibilitado un movimiento importante a pesar de algunas limitaciones. Entre estas últimas podemos señalar el escaso calado o la limitada explanada comercial de algunos puertos como Órzola y Caleta del Sebo que, sin embargo, posibilitaron el tránsito de más de 300 mil pasajeros en 2015. Por el contrario, el puerto de Las Palmas de Gran Canaria, además en expansión en la actualidad, cuenta con cuatro rampas para ferry, además de una extensa explanada comercial y de línea de atraque. Pero tendríamos que señalar algunos puertos como el de Agaete y el de Los Cristianos, donde las actuales cifras de movimiento de pasajeros y de vehículos, dejan en entredicho la escasa capacidad infraestructural de estos puertos y, por tanto, un obstáculo para el tránsito rápido de las unidades de tráfico que preconiza el Eje Transinsular.

Tabla 5. Características principales de los puertos canarios como apoyo al Eje Transinsular de Transportes en diciembre de 2016*

\begin{tabular}{|l|c|c|c|c|}
\hline Puertos & $\begin{array}{c}\text { Longitud atraque } \\
\text { comercial (ms.) }\end{array}$ & $\begin{array}{c}\text { Rampas ferry } \\
\text { atraque } \\
\text { comercial }\end{array}$ & $\begin{array}{c}\text { Calado } \\
\text { medio }\end{array}$ & $\begin{array}{c}\text { Explanada } \\
\text { comercial } \\
\text { (ms.) }\end{array}$ \\
\hline Caleta del Sebo (La Graciosa) & 112 & 0 & 5 & 9000 \\
\hline Órzola (Lanzarote) & 95 & 0 & 3 & 1300 \\
\hline Playa Blanca (Lanzarote) & 266 & 2 & 5 & 19500 \\
\hline Corralejo (Fuerteventura) & 320 & 2 & 6 & 28200 \\
\hline Morro Jable (Fuerteventura & 340 & 2 & 9 & 75231 \\
\hline $\begin{array}{l}\text { Las Palmas G.C. } \\
\text { (Gran Canaria) }\end{array}$ & 971 & 4 & 10 & 121580 \\
\hline Agaete (Gran Canaria) & 190 & 1 & 6 & 22026 \\
\hline S/C de Tenerife (Tenerife) & 456 & 3 & 9 & 31570 \\
\hline Los Cristianos (Tenerife) & 230 & 2 & 6 & 16720 \\
\hline S.S. La Gomera (La Gomera) & 270 & 2 & 9 & 14950 \\
\hline S/C de La Palma (La Palma) & 415 & 3 & 10 & 21527 \\
\hline Valverde (El Hierro) & 373 & 2 & 12 & 10250 \\
\hline
\end{tabular}

Leyenda: * Solo se consideran los diques, calados, rampas y explanadas para el uso interinsular.

Fuente: elaboración propia a partir de las Memorias Anuales de Puertos del Estado y de las Memorias Anuales de Puertos canarios (2017) 
Por todo ello, exponemos a continuación las principales actuaciones previstas en los puertos que, en 2016, contaban con proyectos de ampliación y mejora y que, evidentemente, coinciden a grandes rasgos con los que presentan mayores problemas de operatividad en la actualidad. De este modo, la transformación prevista para la docena de puertos mencionada, se va a centrar sobre todo en cinco: Playa Blanca, Corralejo, Las Palmas de Gran Canaria, Agaete y Los CristianosFonsalía, pues las actuales limitaciones infraestructurales van a ser en gran parte solventadas con las actuaciones previstas. Es el caso por ejemplo del puerto de Agaete que, con la transformación proyectada, permitirá la entrada en operatividad de otra naviera, después de más de 20 años en el que solo ha podido operar Fred. Olsen debido a las citadas limitaciones. $\bigcirc$ también el reemplazo del puerto de Los Cristianos por el de Fonsalía, con importantes déficits el primero para el gran volumen de tráfico que presenta, al tiempo que la terminación del Muelle de la Esfinge convertirá al puerto de La Luz y de Las Palmas en la mejor infraestructura de las Islas para el tráfico interinsular.

Son pues estas actuaciones las que contribuirán a fortalecer el éxito del pretendido Eje Transinsular, aunque aún así seguirán existiendo importantes fortalezas y debilidades, en parte achacables a las propias infraestructuras portuarias, o también a la accesibilidad terrestre hasta o desde ellas.

Tabla 6. Principales actuaciones previstas susceptibles de utilización por el tráfico marítimo interinsular en los puertos del Eje Transinsular en diciembre de 2016

\begin{tabular}{|l|c|c|c|c|c|c|}
\cline { 2 - 7 } \multicolumn{1}{c|}{} & \multicolumn{2}{c|}{$\begin{array}{c}\text { Longitud atraque } \\
\text { comercial (ms.) }\end{array}$} & \multicolumn{2}{c|}{$\begin{array}{c}\text { Rampa ferry } \\
\text { atraque comercial }\end{array}$} & \multicolumn{2}{c|}{$\begin{array}{c}\text { Explanada comercial } \\
\text { (ms.) }\end{array}$} \\
\hline Puertos & Actual & Futura & Actual & Futura & Actual & Futura \\
\hline Playa Blanca (Lanzarote) & 266 & 570 & 2 & 2 & 19500 & 73200 \\
\hline Corralejo (Fuerteventura) & 320 & 480 & 2 & 2 & 28200 & 49300 \\
\hline Morro Jable (Fuerteventura) & 768 & 768 & 2 & 2 & 75231 & 78305 \\
\hline $\begin{array}{l}\text { Las Palmas G.C. } \\
\text { (Gran Canaria) }\end{array}$ & 971 & 2540 & 4 & 6 & 121580 & 196800 \\
\hline Agaete (Gran Canaria) & 190 & 550 & 1 & 3 & 22026 & 73200 \\
\hline Los Cristianos (Tenerife)* $^{*}$ & 230 & 850 & 2 & 4 & 16720 & 151700 \\
\hline
\end{tabular}

Leyenda: * Está previsto que el puerto de Los Cristianos sea reemplazado para las conexiones marítimas interinsulares por el de Fonsalía, 19 kilómetros más al norte, exponiéndose aquí las características básicas futuras de este último.

Fuente: elaboración propia a partir de las Memorias Anuales de Puertos del Estado y de las Memorias Anuales de Puertos canarios (2017)

\subsection{El sistema de carreteras del Eje Transinsular}

Si la infraestructura portuaria es esencial para el desarrollo del Eje Transinsular, las carreteras en cada isla que conectan con estos puertos no lo son menos. De todos modos, y si bien es verdad que todas las islas cuentan con algún tramo considerado dentro de dicho Eje, existen al menos tres que son vitales para la consecución de los objetivos que se persiguen con esta política, como es el que una unidad de tráfico, como ya argumentamos, pueda atravesar el Archipiélago en una 
jornada e incluso que el vehículo que transportó esa mercancía pueda regresar al punto de retorno dentro del mismo día. Esas tres vías son las que conectan Corralejo con Morro Jable en Fuerteventura (de 121 kilómetros); Las Palmas de Gran Canaria-Agaete en Gran Canaria (34 kilómetros); y Santa Cruz de Tenerife-Los Cristianos en Tenerife (76 kilómetros), pues ellas no solo son el soporte de la canalización de las unidades de tráfico que tiene lugar dentro de cada una de esas islas, sino que, a su vez, sirven de tránsito para el tráfico generado en las restantes islas.

De todos modos, las obras de carreteras actualmente en ejecución y las que se preveían realizar dentro del Convenio de carreteras entre el Ministerio de Fomento y el Gobierno de Canarias $-y$ que aún está en vigor a pesar de la falta de financiación debido a la crisis económica-, cumplen en su mayor parte con los objetivos del Eje Transinsular de Transportes, pues aunque algunos de estos proyectos no se incluyen íntegramente dentro del mencionado Eje Transinsular, sí que cumplen con una función muy importante de proporcionar accesibilidad a este eje de movilidad principal entre las Islas. Destacamos en la tabla 7 -en negrita y cursiva-, los tramos de carretera que se insertan directamente dentro del Eje Transinsular y que sirven de soporte para la conexión con los puertos comarcales, indicando en cada caso, además del presupuesto, el grado de ejecución a fecha de 2016.

Tabla 7. Actuaciones que estaban previstas en el Convenio de carreteras de 2006 entre el Ministerio de Fomento y el Gobierno de Canarias y situación en diciembre de 2016

\begin{tabular}{|l|c|}
\hline Actuaciones previstas entre 2006 y 2017 & $\begin{array}{c}\text { Presupuesto } \\
\text { (millones de euros) }\end{array}$ \\
\hline Santiago del Teide - Adeje y enlace al puerto de Fonsalía (en ejecución) & 214,23 \\
\hline $\begin{array}{l}\text { Circunvalación área metropolitana de Tenerife: } \\
\text { Padre Anchieta - Los Rodeos (en ejecución) }\end{array}$ & 170,01 \\
\hline Icod - Santiago del Teide (1' fase); tramo: Icod - El Tanque (en servicio) & 132,33 \\
\hline Icod - Santiago del Teide; tramo: El Tanque - Santiago del Teide (no ejecutada) & 129,38 \\
\hline Los Realejos - Icod; tramo San Juan de La Rambla - Icod (no ejecutada) & 64,90 \\
\hline Avenida Tres de mayo - Guajara 2 fase (Ofra - El Chorrillo) (en ejecución) & 9,00 \\
\hline Subtotal Tenerife & 719,85 \\
\hline Puerto Rico - Mogán (en servicio) & 121,31 \\
\hline Circunvalación Las Palmas fase IV: Tamaraceite - Tenoya - Arucas Costa (en servicio) & 105,75 \\
\hline Agaete - La Aldea de San Nicolás; tramo: La Aldea - El Risco (en ejecución) & 103,70 \\
\hline Arucas - Pagador, variante de Bañaderos (ejecución parcial) & 75,00 \\
\hline Pagador - Guía (ejecución parcial) & 63,50 \\
\hline Subtotal Gran Canaria & 469,26 \\
\hline La Cumbre - Los Llanos de Aridane (no ejecutada) & 86,30 \\
\hline Llano Negro - Puntagorda (no ejecutada) & 48,60 \\
\hline Bajamar - Tajuya (ejecución parcial) & 45,00 \\
\hline San Andrés y Sauces - Barlovento - Cruz del Castillo (ejecución parcial) & 44,52 \\
\hline Subtotal La Palma & 224,42 \\
\hline La Caldereta - Corralejo y Valluelo - Vinamar (en ejecución) & 68,75 \\
\hline Aeropuerto - Pozo Negro (no ejecutada) & 43,20 \\
\hline Puerto del Rosario - La Caldereta (en licitación) & 31,73 \\
\hline Costa Calma - Pecenescal (ejecución parcial) & 24,68 \\
\hline Subtotal Fuerteventura & 168,36 \\
\hline Yaiza - Arrecife (ejecución parcial) & 51,66 \\
\hline Circunvalación de Arrecife (en servicio) & 45,83 \\
\hline
\end{tabular}


Tabla 7. Continuación

\begin{tabular}{|l|c|}
\hline Actuaciones previstas entre 2006 y 2017 & $\begin{array}{c}\text { Presupuesto } \\
\text { (millones de euros) }\end{array}$ \\
\hline Arrecife - Tahíche (ejecución parcial) & 28,40 \\
\hline Guatiza - Órzola (no ejecutada) & 20,38 \\
\hline Subtotal Lanzarote & 146,27 \\
\hline Arure - Alajeró (no ejecutada) & 44,80 \\
\hline Travesía de Hermigua (en ejecución) & 30,60 \\
\hline Vallehermoso - Arure (1ª fase) (ejecución parcial) & 23,22 \\
\hline Alajeró - aeropuerto (no ejecutada) & 14,00 \\
\hline Subtotal La Gomera & 112,62 \\
\hline Frontera - Sabinosa (en ejecución) & 18,00 \\
\hline Subtotal El Hierro & 18,00 \\
\hline TOTAL (obras previstas en Canarias) & 1858,78 \\
\hline TOTAL (obras en ejecución y también financiadas por el Ministerio de Fomento) & 290,22 \\
\hline TOTAL (expropiaciones sobre las obras previstas) & 288,00 \\
\hline SUMA DE TODOS LOS CONCEPTOS & 2437,00 \\
\hline
\end{tabular}

Fuente: Convenio de carreteras entre el Ministerio de Fomento y el Gobierno de Canarias de 31 de enero de 2006 (Ministerio de Fomento, 2006)

Realizamos a continuación una síntesis de las fortalezas y debilidades que presentan en la actualidad las principales vías terrestres susceptibles de utilización por una mercancía rodada en el Eje Transinsular, destacando para ello los tramos de las islas de Tenerife, Gran Canaria y Fuerteventura, aunque añadiendo Lanzarote, ya que desde la isla de La Graciosa -o hacia ésta-, también se podría generar movilidad de mercancías. No obstante, hay que decir que las embarcaciones que operan en la actualidad la línea Órzola-Caleta del Sebo, no admiten carga rodada, pues no son tipo ferry, estibándose las escasas mercancías a través de pequeñas grúas, o más usualmente, utilizando simplemente la fuerza humana para ello.

En suma, si las actuales vías que sirven de soporte para canalizar el tráfico marítimo intercomarcal entre islas presentan un buen estado en general, por otro, la debilidad principal se centra en los problemas de congestión, especialmente en las primeras y últimas horas del día, sobre todo en el tramo Las Palmas de Gran Canaria-Agaete. También es importante señalar que el acceso a determinados puertos -principalmente el de Los Cristianos y los capitalinos de Tenerife y Gran Canaria, aunque cada vez más también los de Playa Blanca, Corralejo, Morro Jable y Agaete-, sufren congestión viaria derivado del crecimiento urbano entorno a los citados puertos, por lo que en algunos casos como el de Los Cristianos, éste es uno de los grandes justificantes para la construcción de una nueva infraestructura portuaria que no soporte estos inconvenientes. 
Tabla 8. Principales fortalezas y debilidades de las infraestructuras de carreteras que sirven de apoyo al Eje Transinsular de Transportes en diciembre de 2016

\begin{tabular}{|l|l|l|}
\hline Carreteras & \multicolumn{1}{|c|}{ Fortalezas } & \multicolumn{1}{|c|}{ Debilidades } \\
\hline Órzola - Playa Blanca & $\begin{array}{l}\text { 1) Distancia aceptable. } \\
\text { 2) Buen estado en general de la } \\
\text { vía. } \\
\text { 3) No hay problemas de } \\
\text { atascos. }\end{array}$ & $\begin{array}{l}\text { 1) Varios tramos de mejora (en } \\
\text { especial desdoblamiento) sin } \\
\text { ejecutar. }\end{array}$ \\
\hline Corralejo - Morro Jable & $\begin{array}{l}\text { 1) Buen estado en general de la } \\
\text { vía. } \\
\text { 2) No hay problemas de } \\
\text { atascos. }\end{array}$ & $\begin{array}{l}\text { 1) Distancia importante. } \\
\text { 2) Varios tramos de mejora (en } \\
\text { especial desdoblamiento) sin } \\
\text { ejecutar. }\end{array}$ \\
\hline Las Palmas G.C. - Agaete & $\begin{array}{l}\text { 1) Distancia aceptable. } \\
\text { 2) Buen estado en general de la la } \\
\text { vía. }\end{array}$ & $\begin{array}{l}\text { 1) Tramo urbano San Andrés - } \\
\text { Pagador sin ejecutar. } \\
\text { 2) Problemas de concentración } \\
\text { horaria de vehículos. }\end{array}$ \\
\hline S/C Tenerife - Cristianos & $\begin{array}{l}\text { 1) Buen estado en general de la } \\
\text { vía. } \\
\text { 2) Los atascos, aunque existen, } \\
\text { son muy puntuales. }\end{array}$ & $\begin{array}{l}\text { 1) Distancia importante. } \\
\text { 2) El acceso a y desde el puerto } \\
\text { de Los Cristianos es deficitario. }\end{array}$ \\
\hline
\end{tabular}

Fuente: elaboración propia a partir de la Consejería de Obras Públicas

y Transportes del Gobierno de Canarias (2016)

\subsection{La accesibilidad horaria}

Además de los problemas imputables a las infraestructuras a lo que ya hemos aludido más arriba, una de las claves del éxito del Eje Transinsular de Transportes, se refiere a los horarios de los operadores marítimos, en tanto que la verdadera integración territorial se constata en la capacidad de las unidades de tráfico para desplazarse por toda la red interinsular dentro de una misma jornada. Y ello no se consigue necesariamente a través de un aumento de las frecuencias, sino de una eficiente coordinación horaria (Chowdhury, 2015). En efecto, la clave se encuentra en el cotejo de los horarios de llegada a un puerto, más los tiempos de transporte terrestre y de facturación en el otro puerto de tránsito de la misma isla, de tal modo que permitan un enganche sin prácticamente esperas. Esto es vital en las principales islas de tránsito del Eje Transinsular, como son Fuerteventura, Gran Canaria y Tenerife, islas éstas que cuentan cada una con dos puertos que son fundamentales para el normal desarrollo del citado Eje Transinsular.

Partimos de la base de que los tiempos de conducción terrestre en Canarias no presentan ningún inconveniente para la potenciación del Eje Transinsular, pues según el Reglamento CE 561/2006, se permite una conducción continuada con vehículos industriales hasta las 4,5 horas, tras el que el conductor deberá realizar una parada de al menos 45 minutos, a la vez que un máximo de nueve horas diarias al volante y un descanso diario de 11 horas ininterrumpidas, cuestión esta última que se podría solventar con un segundo conductor aunque repercutiendo evidentemente en los costes 
del transporte. ${ }^{3}$ Por tanto, a los trayectos analizados, no les repercute negativamente en Canarias el citado Reglamento.

Pues bien, la situación actual dista bastante de la ideal, pues haciendo uso del transporte marítimo y terrestre, una mercancía rodada no debiera contar con una demora para el embarque superior a los 60 o 70 minutos en los puertos y la situación actual nos indica que en un desplazamiento entre las islas más orientales y occidentales -alternando el transporte marítimo con el viario en las tres islas de tránsito mencionadas-, el viaje se ve interrumpido dentro de una misma jornada en alguna de ellas. En efecto, en la actualidad existe una muralla infranqueable en el embarque hacia Gran Canaria desde Tenerife cuando el desplazamiento procede desde las islas occidentales y en Fuerteventura cuando la mercancía parte desde Lanzarote. Ello obliga a pernoctar en alguna de las islas, incrementando considerablemente el coste de los envíos, cuando no los restringe por completo. Y es que la existencia de una pernoctación no favorece la movilidad interinsular, pues el coste de ésta más el de las dietas alimenticias y de las horas laborales perdidas, conlleva muchas veces un coste superior al del viaje interinsular en sí.

En la siguiente tabla se ha considerado la "situación actual" aunque, a todos los efectos, se debiera estimular conectividades horarias próximas a la situación ideal que también exponemos. Tomamos la salida más inmediata, independientemente de la naviera, aunque ello no termina siendo del todo viable, ya que las navieras priman económicamente el viaje en su propia compañía cuando se transborda de una isla a otra, por ejemplo La Gomera-Gran Canaria (vía Tenerife), hecho que, casi siempre, obliga a la unidad de tráfico a desplazarse en una frecuencia no óptima, más tardía por ejemplo, si la mercancía -o urgencia del pasajero-, no indican lo contrario.

Tabla 9. Simulación horaria de una mercancía rodada en una jornada laboral entre Lanzarot y las islas occidentales a través del Eje Transinsular de Transportes en diciembre de 2016*

\begin{tabular}{|l|c|c|}
\hline Tramos del transporte & Horario actual & Horario ideal** \\
\hline Salida del puerto de Playa Blanca (Lanzarote) & 07.00 (N.A.) & 07.00 \\
\hline Llegada puerto de Corralejo (Fuerteventura) & 07.35 & 07.35 \\
\hline Tiempo de desembarco en Corralejo (Fuerteventura) & 07.40 & 07.40 \\
\hline Tramo terrestre Corralejo - Morro Jable (Fuerteventura) & 09.30 & 09.30 \\
\hline Salida del puerto de Morro Jable (Fuerteventura) & 16.00 (N.A.) & 10.00 \\
\hline Llegada puerto de Las Palmas de G.C. (Gran Canaria) & 19.20 & 12.30 \\
\hline $\begin{array}{l}\text { Tiempo de desembarco en Las Palmas G.C. (Gran } \\
\text { Canaria) }\end{array}$ & 19.30 & 12.40 \\
\hline Tramo terrestre Las Palmas G.C. - Agaete (Gran Canaria) & 20.10 & 13.20 \\
\hline Salida del puerto de Agaete (Gran Canaria) & -- & 14.00 \\
\hline Llegada puerto de S/C de Tenerife (Tenerife) & - & 15.20 \\
\hline
\end{tabular}

3 Reglamento (CE) 561/2006 del Parlamento Europeo y del Consejo de 15 de marzo de 2006 relativo a la armonización de determinadas disposiciones en materia social en el sector de los transportes por carretera. Diario Oficial de la Unión Europea, 11/04/2006. 


\section{Tabla 9. Continuación}

\begin{tabular}{|l|c|c|}
\hline Tramos del transporte & Horario actual & Horario ideal $^{* *}$ \\
\hline Tiempo de desembarco en S/C de Tenerife (Tenerife) & -- & 15.30 \\
\hline Tramo terrestre S/C de Tenerife - Los Cristianos (Tenerife) & -- & 16.30 \\
\hline Salida puerto de Los Cristianos - La Gomera (Tenerife) & -- & 17.00 \\
\hline Llegada puerto de San Sebastián La Gomera (La Gomera) & -- & 17.50 \\
\hline Salida puerto de Los Cristianos - La Palma (Tenerife) & -- & 17.00 \\
\hline Llegada puerto de Santa Cruz de La Palma (La Palma) & -- & 19.30 \\
\hline Salida puerto de Los Cristianos - El Hierro (Tenerife) & -- & 17.00 \\
\hline Llegada puerto de Valverde (El Hierro) & -- & 19.30 \\
\hline
\end{tabular}

Leyenda: * La mercancía rodada se simula en un furgón grande, capaz de desarrollar una velocidad comercial media de $65 \mathrm{~km} / \mathrm{h}$ y, teóricamente, sin congestión viaria. Tomamos los horarios oficiales de las navieras vigentes a 31 de diciembre de 2016. En este caso, siempre se toma el horario de partida de los puertos con salida más inmediata. / ** Horario ideal con tecnología fast ferry.

Fuente: elaboración propia a partir de Navieras, Consejería de Obras Públicas

y Transportes del Gobierno de Canarias (2016)

Como se deduce de la tabla anterior, la conexión desde la isla de Lanzarote hasta las islas más occidentales podríamos calificarla actualmente como muy mala, pues solo es posible alcanzar Gran Canaria tras hacer escala en los puertos de Corralejo y Morro Jable en Fuerteventura, después de permanecer más de seis horas en este último puerto en demanda de la siguiente frecuencia con Gran Canaria. Debido a ello, no es posible que el transporte pueda enganchar con la frecuencia de las 20.00 horas en Agaete que, al menos, lo transporte a Tenerife, isla ésta que si tiene un ostensible movimiento de unidades de tráfico con las islas periféricas orientales. La situación ideal que también modelamos en la tabla anterior, donde los tiempos de tránsito en los puertos son los mínimos, alrededor de 30 minutos, demostramos que se pueden alcanzar perfectamente las islas periféricas occidentales en la misma jornada, si bien no es posible regresar a la isla de origen (en este caso Lanzarote) dentro del mismo día.

En la situación inversa, es decir, desde La Palma a Lanzarote, la situación actual tampoco es favorable, pero bastante mejor en relación con el sentido naciente-poniente, pues se puede realizar el tránsito en tres islas (Tenerife, Gran Canaria y Fuerteventura), aunque queda pendiente la travesía a Lanzarote, implicando necesariamente una pernoctación en Fuerteventura, más otra en el sentido inverso, en total, tres jornadas de viaje en un round trip. De todos modos, como demostramos en la siguiente tabla, existen casi cuatro horas de espera en la salida del puerto de Santa Cruz de Tenerife, a lo que habría que sumarle casi cinco en el de Las Palmas de Gran Canaria, implicando estas nueve horas más tiempo que el empleado en el transporte marítimo y terrestre hasta la capital grancanaria. Sin embargo, en la situación ideal señalamos que incluso es posible iniciar el retorno en la misma jornada tras alcanzar Lanzarote y emplear allí dos horas en la desestiba -y estiba de la mercancía- si fuese necesario, aunque a la vuelta sería ineludible la pernoctación en Fuerteventura, 
ya que excluimos la navegación nocturna en aras de cumplir además con el reglamento de descanso de los conductores de vehículos industriales.

Tabla 10. Simulación horaria de una mercancía rodada en una jornada laboral entre La Palma y Lanzarote a través del Eje Transinsular de Transportes en diciembre de 2016*

\begin{tabular}{|l|c|c|}
\hline Tramos del transporte & Horario actual & Horario ideal** \\
\hline Salida del puerto de S/C de La Palma (La Palma) & 04.00 (N.A.) & 05.30 \\
\hline Llegada al puerto de Los Cristianos (Tenerife) & 08.00 & 08.00 \\
\hline Tiempo de desembarco en Los Cristianos (Tenerife) & 08.10 & 08.10 \\
\hline Tramo terrestre Los Cristianos - S/C de Tenerife (Tenerife) & 09.10 & 09.10 \\
\hline Salida del puerto de S/C de Tenerife (Tenerife) & 13.00 (F.O.) & 09.30 \\
\hline Llegada puerto de Agaete (Gran Canaria) & 14.20 & 10.50 \\
\hline Tiempo de desembarco en Agaete (Gran Canaria) & 14.30 & 11.00 \\
\hline Tramo terrestre Agaete - Las Palmas G.C. (Gran Canaria) & 15.10 & 11.40 \\
\hline Salida del puerto de Las Palmas de G.C. (Gran Canaria) & 20.00 (F.O.) & 12.00 \\
\hline Llegada puerto de Morro Jable (Fuerteventura) & 22.30 & 14.45 \\
\hline Tiempo de desembarco en Morro Jable (Fuerteventura) & 22.40 & 14.55 \\
\hline Tramo terrestre Morro Jable - Corralejo (Fuerteventura) & 00.30 & 16.45 \\
\hline Salida puerto de Corralejo (Fuerteventura) & -- & 17.00 \\
\hline Llegada puerto de Playa Blanca (Lanzarote) & -- & 17.25 \\
\hline Tiempo de desembarco en Playa Blanca (Lanzarote) & -- & 17.30 \\
\hline 2 horas en Lanzarote para desembarque mercancías & -- & 19.30 \\
\hline
\end{tabular}

Leyenda: * La mercancía rodada se simula en un furgón grande, capaz de desarrollar una velocidad comercial media de 65 kms./h. y, teóricamente, sin congestión viaria. Tomamos los horarios oficiales de las navieras vigentes a 31 de diciembre de 2016. En este caso, siempre se toma el horario de partida de los puertos con salida más inmediata. / ** Horario ideal con tecnología fast ferry.

Fuente: elaboración propia a partir de Navieras, Consejería de Obras Públicas y Transportes del Gobierno de Canarias (2016)

En definitiva, la coordinación horaria que ofertan actualmente las navieras en aras de la potenciación del Eje Transinsular de Transportes, es bastante deficiente, hecho que si se planificase adecuadamente como hemos demostrado con alternativas horarias perfectamente viables, contribuiría a mejorar sus cuentas de resultados y, de paso, la integración territorial de las Islas.

\subsection{La accesibilidad económica}

La capacidad de movilidad de una unidad de tráfico (pasajero o mercancía), es otro parámetro fundamental que nos acerca a la importancia económica de los territorios (Tindemans, 2005), pero también al grado de integración territorial de una isla con respecto a las restantes (Hernández Luis, 2002).

Sin embargo, la cuantía económica que un ciudadano o empresa desembolsa al hacer uso de un servicio de transporte no es exacta, pues el sistema de tarifas es un entramado que, para un trayecto realizado con un mismo operador, día y horario, puede conllevar notables variaciones y, 
además para el caso de las mercancías, bonificaciones por utilización reiterada del servicio de transporte. De esta manera, las tarifas se convierte en un entramado donde si es difícil entrar, más lo es salir con resultados fiables, sobre todo si nos atenemos a las particularidades de cada unidad de tráfico. Por todo ello, es preferible decantarse entonces por un análisis de las tarifas base partiendo de un transporte estándar en furgoneta con mercancía entre islas.

Habría que indicar también que el objetivo del planteamiento de la accesibilidad económica que realizamos en este apartado, persigue un estudio comparativo con el coste de la movilidad en el territorio continental, en línea con lo que propugnan algunos documentos del Gobierno de Canarias, al argumentar que debe ser objetivo del transporte público "la equiparación de los costes de la movilidad a la media que soportan los usuarios de los distintos modos de transporte en territorios continuos" (Gobierno de Canarias, 2001, tomo I, p. 83).

Como se deduce pues de la lectura de la siguiente tabla, hemos calculado que el coste de un transporte en un furgón grande se aproximaba en diciembre de 2016 a los 600 euros de ida entre Lanzarote y La Palma, incluyendo solo el combustible terrestre y las tarifas marítimas. Se excluyen los costes imputables al alquiler o amortización del vehículo, el coste del conductor, las reparaciones, los seguros, etc., pudiendo éstos significar entre un 20 y un $40 \%$ más sobre los costes señalados, es decir, hasta $800 €$ de ida, condicionados sobre todo por la propiedad del vehículo y los tiempos de viaje sujetos a los horarios señalados en el apartado anterior.

\section{Tabla 11. Simulación de la tarifa marítima de ida de una mercancía rodada entre Lanzarote y La Palma a través del Eje Transinsular de Transportes en diciembre de 2016*}

\begin{tabular}{|c|c|c|}
\hline & \multicolumn{2}{|c|}{ Tarifas (en $€$ ) } \\
\hline Tramos del transporte & Fred. Olsen & Armas \\
\hline Coste medio combustible del transporte terrestre en Lanzarote & 3,00 & 3,00 \\
\hline Playa Blanca - Corralejo & 75,76 & 47,65 \\
\hline Coste medio combustible del transporte terrestre en Fuerteventura & 6,00 & 6,00 \\
\hline Morro Jable - Las Palmas de Gran Canaria & 197,70 & 188,46 \\
\hline Coste medio combustible del transporte terrestre en Gran Canaria & 3,00 & 0,00 \\
\hline Agaete - Santa Cruz de Tenerife & 192,24 & $159,35 * *$ \\
\hline Coste medio combustible del transporte terrestre en Tenerife & 5,00 & 5,00 \\
\hline Los Cristianos - Santa Cruz de La Palma & 250,93 & 170,56 \\
\hline Coste medio combustible del transporte terrestre en La Palma & 3,00 & 3,00 \\
\hline $\begin{array}{l}\text { Subtotal (incluyendo } 20 \% \text { de bonificación con la naviera Fred. } \\
\text { Olsen por utilización de más de una línea) }\end{array}$ & 573,30 & 566,02 \\
\hline Total incluyendo coste del combustible del transporte terrestre & 593,30 & 583,02 \\
\hline $\begin{array}{l}\text { Total incluyendo amortización del vehículo, reparaciones, coste del } \\
\text { conductor, etc. (entre un } 20 \text { y } 40 \% \text { más) }\end{array}$ & $\begin{array}{l}711,96- \\
830,62 \\
\end{array}$ & $\begin{array}{c}699,62- \\
816,23 \\
\end{array}$ \\
\hline
\end{tabular}

Leyenda: * El cálculo de la tarifa en ambas navieras se simula para un furgón grande con mercancía. Las tarifas incluyen los recargos por combustibles y las tarifas portuarias. / ** Este trayecto se considera entre Las Palmas de Gran Canaria y Santa Cruz de Tenerife, ya que la Naviera Armas no opera desde Agaete.

Fuente: elaboración propia a partir de Naviera Armas (2016) y Fred. Olsen (2016) 
Pues bien, dicho coste global que, como comentamos, puede superar incluso los 800 euros de ida en un trayecto de 540 kilómetros, incluyendo los itinerarios terrestres y marítimos entre el puerto de Santa Cruz de La Palma y el de Playa Blanca en Lanzarote (vía Tenerife, Gran Canaria y Fuerteventura), suponen unos costes entre 1,30 y 1,54 euros por kilómetro, frente a los 1,05 en la Península Ibérica, ${ }^{4}$ esto es, unos 570 euros para el mismo trayecto en territorio continental. En suma, desplazar una mercancía en Canarias en un furgón grande supone como mínimo un 35 \% más oneroso en relación con el territorio continental, elevándose aún más este coste entre los vehículos de mayor tonelaje. Evidentemente, este es otro factor que no contribuye en absoluto a la integración territorial de las Islas y, por ende, otra asignatura pendiente del Eje Transinsular de Transportes.

\section{Aproximación al balance ambiental del Eje Transinsular}

Realizamos aquí una aproximación muy breve al balance ambiental que supone operar una embarcación interinsular en Canarias, tomando para ello el ejemplo de una de las rutas con mayor densidad de frecuencias y de tráfico, como es Gran Canaria-Tenerife. Partimos del consumo de combustible de las embarcaciones y también del incremento de la distancia que supone la utilización de un puerto u otro entre ambas islas centrales, pues la línea es operada con Tenerife desde el mismo puerto capitalino de dicha Isla, pero con Gran Canaria a través de dos puertos: Agaete y Las Palmas de Gran Canaria.

Como hemos argumentado, la filosofía del Eje Transinsular de Transportes, potencia la conexión a través de los puertos comarcales más cercanos entre islas, con lo que en este caso, es el puerto de Agaete el más óptimo para esta conexión a través del Eje, pues la distancia marítima entre los puertos de Santa Cruz de Tenerife y el de Agaete es de 36 millas náuticas (67 km) y entre el primero y el de Las Palmas de Gran Canaria de 51 millas (94km), con lo que la conexión marítima con este último presenta una distancia un $40 \%$ mayor.

También hay que argumentar que en el puerto de Agaete solo opera una naviera (Fred. Olsen), si bien desde hace años ha solicitado entrar en este corredor el otro gran operador marítimo interinsular (la Naviera Armas). Argumentamos ello porque las tecnologías con las que operan ambas navieras son diferentes, ya que la primera realiza sus trayectos con fast ferry y una velocidad de crucero media entre los 36 y 38 nudos, con un mayor consumo de combustible y, además, tipo diésel, mientras que la Naviera Armas desde Las Palmas de Gran Canaria emplea embarcaciones

4 El dato que nos ofrece la fuente es de exactamente 1,01€ por kilómetro para 2011, aunque lo hemos corregido en función de la inflación hasta los 1,05 euros por kilómetro de 2016 (Ministerio de Fomento, 2011). 
tipo ferry y combustible pesado fueloil, ${ }^{5}$ alcanzando velocidades de crucero entorno a los 22-24 nudos.

Pues bien, para el cálculo del consumo de combustible, habría que comentar también que inciden multitud de circunstancias, como por ejemplo el estado y desplazamiento del buque (nivel de limpieza del casco, porcentaje de carga en cada travesía, etc.), también las condiciones del tiempo y el estado de la mar, el poder calorífico y densidad del combustible, la tipología de pinturas aplicadas en los cascos de las embarcaciones con el fin de reducir la resistencia de fricción, el perfil operativo de los buques, etc.

En cualquier caso, partimos de datos reales facilitados por las navieras, considerando un consumo medio de ida y vuelta de los dos buques de Fred. Olsen en el corredor Agaete-Santa Cruz de Tenerife (Bencomo Express y Bentago Express, ambos con consumo diésel) y para la Naviera Armas (Volcán de Tamadaba, con consumo de fueloil). Para el transporte terrestre, tomamos como ejemplo una furgoneta de tamaño grande con un insumo medio estimado, según el Observatorio de Transportes del Gobierno de Canarias, de 13 I/100 km y de 7//100 km para los vehículos tipo turismos. Partiendo de la base del volumen real de turismos y de vehículos industriales para el año 2015 (eligiendo el citado "furgón grande" como media en este último caso) y los mencionados consumos medios, obtenemos el insumo medio resultante. Hay que destacar que gran parte de la actividad económica en la isla de Gran Canaria se localiza en la propia capital de la Isla, así como en el Este y Sur insular, por lo que el transporte terrestre hasta y desde los puertos es de $30 \mathrm{~km}$ de media con el puerto de Las Palmas de Gran Canaria y de 100 km con el puerto noroccidental de Agaete.

Como se deduce de los resultados de la tabla anterior, en el balance final, partiendo de los datos reales del movimiento de vehículos terrestres en este corredor marítimo, se llega a la conclusión de que, a priori, es medioambientalmente preferible la utilización del puerto de Agaete, como infraestructura más cercana a Tenerife, aunque empleando buques tipo ferry, si bien ello incrementaría el trayecto desde los 80 a los 120 minutos, repercutiendo posiblemente en un ostensible descenso del tráfico y contraviniendo la filosofía del Eje Transinsular de Transportes en el que la velocidad marítima es una pieza clave. A su vez, en las condiciones actuales de la demanda, la ruta Las Palmas de Gran Canaria-Santa Cruz de Tenerife en ferry, supone un ahorro de combustible del 19 \% y llegaría al $15 \%$ si en este corredor se canalizara toda la demanda que utiliza el puerto de Agaete. Pero la diferencia más importante, como decíamos, tiene lugar con la

5 Hacemos hincapié en el tipo de combustible, ya que el coste de explotación de las navieras también depende del diferencial existente entre el fueloil y el diésel. Así, a 31 de diciembre de 2016 -y según las estadísticas de la U. S. Energy Information Administration-, el precio del primero ascendía en el mercado internacional a 1,47 € el galón, frente a los 1,56 euros del diésel. Ello significaba un 6,12 \% más elevado este último, si bien el diferencial ha alcanzado hasta un $15 \%$ en el pasado. 
utilización del ferry en Agaete, en lugar del actual fast ferry, llegando entonces a un ahorro energético del 35 \%. Así pues, aparentemente, la utilización de un ferry con y desde el puerto comarcal de Agaete, presenta un mejor balance ambiental basado en demanda real, en relación con la alternativa desde la capital grancanaria o el fast ferry desde Agaete.

Por su parte, aplicando una simulación a plena carga de los buques que operan en esas rutas, lo primero que destaca es el gasto extra de combustible que supone la navegación en fast ferry, pues esta supondría casi el doble por vehículo frente a la utilización de un ferry desde el puerto de Agaete (56 litros por vehículo frente a los 30 del ferry). Pero si se compara la operación en ferry desde Las Palmas de Gran Canaria o desde Agaete con Tenerife, el balance energético resulta un 10 \% favorable a este último, con lo que la utilización del puerto de Agaete vuelve a destacar positivamente con la simulación de los buques actuales a plena carga.

\section{Tabla 12. Simulación del consumo medio de combustible en viaje de ida y vuelta en el corredor marítimo Gran Canaria-Tenerife en 2015*}

\begin{tabular}{|l|c|c|c|}
\hline $\begin{array}{l}\text { Consumo } \\
\text { combustible }\end{array}$ & $\begin{array}{c}\text { Las Palmas de G.C. - } \\
\text { S/C de Tenerife (ferry) }\end{array}$ & $\begin{array}{c}\text { Agaete - S/C de Tenerife } \\
\text { (fast ferry) }\end{array}$ & $\begin{array}{c}\text { Agaete - S/C de Tenerife } \\
(\text { ferry })^{* *}\end{array}$ \\
\hline Marítimo real & 11200 & 13000 & 8000 \\
\hline Terrestre real & $\begin{array}{c}287 \text { (media de } 82 \text { turismos } \\
\text { y 28 vehículos industriales } \\
\text { frecuencia de ida y vuelta) }\end{array}$ & $\begin{array}{c}1.104 \text { (media de 115 } \\
\text { turismos y 23 vehículos } \\
\text { industriales / frecuencia de } \\
\text { ida y vuelta) }\end{array}$ & $\begin{array}{c}1.104 \text { (media de 115 } \\
\text { turismos y 23 vehículos } \\
\text { industriales / frecuencia de } \\
\text { ida y vuelta) }\end{array}$ \\
\hline $\begin{array}{l}\text { Consumo total } \\
\text { sobre } \\
\text { demanda real }\end{array}$ & 11487 & 14104 & 9104 \\
\hline $\begin{array}{l}\text { Consumo por } \\
\text { vehículo a } \\
\text { demanda real }\end{array}$ & 104 & 102 & 66 \\
\hline $\begin{array}{l}\text { Marítimo a } \\
\text { plena carga }\end{array}$ & 12300 & 14300 & 8800 \\
\hline $\begin{array}{l}\text { Terrestre con } \\
\text { ocupación } \\
\text { buque } 100 \%\end{array}$ & $\begin{array}{c}1040 \text { (300 turismos y 105 } \\
\text { vehículos industriales } /\end{array}$ & $\begin{array}{c}2248 \text { (271 turismos y 27 } \\
\text { vehículos industriales } / \\
\text { frecuencia de ida y vuelta) }\end{array}$ & $\begin{array}{c}3465 \text { (300 turismos y } 105 \\
\text { vehículos industriales } / \\
\text { frecuencia de ida y vuelta) }\end{array}$ \\
\hline $\begin{array}{l}\text { Consumo total } \\
\text { a plena carga }\end{array}$ & 13340 & 16548 & 12265 \\
\hline $\begin{array}{l}\text { Consumo por } \\
\text { vehículo a } \\
\text { plena carga }\end{array}$ & 33 & 56 & 30 \\
\hline
\end{tabular}

Leyenda: * Consumo en litros por trayecto de ida y vuelta. / ** No existe operación con ferry desde el puerto de Agaete. Sin embargo, introducimos esta simulación con el ferry de la Naviera Armas, pero con los datos del volumen de tráfico de Fred. Olsen desde dicho puerto, para así evaluar con distintas tecnologías y distancias el impacto del consumo de combustibles del puerto comarcal de Agaete

Fuente: elaboración propia a partir de Naviera Armas, Fred. Olsen

y Dirección General de Transportes del Gobierno de Canarias (2015) 
De todos modos, éste es un planteamiento que supera con creces el objetivo real de este artículo que es el de evaluar la capacidad de integración territorial que emana de la política del Eje Transinsular de Transportes, pues a esta aproximación al balance ambiental de la utilización de un puerto u otro, habría que estudiar con mayor profundidad otros aspectos que también habría que introducir para un proyecto de mayor amplitud, como por ejemplo las consecuencias del incremento de la movilidad terrestre que genera el puerto de Agaete frente al de Las Palmas de Gran Canaria (una media de $100 \mathrm{~km}$ desde y al resto de la Isla, frente a los 30 en trayecto de ida y vuelta del puerto capitalino) y que inciden en la economía en general. Ejemplo de esto es el importante proyecto de ampliación del puerto de Agaete, con una sustancial inyección económica y un gran consumo energético en su construcción, al igual que las obras de la carretera entre la capital grancanaria y el puerto de Agaete que se han realizado -y aún están pendientes-, con consecuencias además paisajísticas, el monto anual en la conservación de esta vía, la congestión viaria que ello causa de manera muy puntual, etc. De igual manera, no solo es el combustible el principal insumo de los vehículos terrestres -en especial cuando la distancia aumenta-, sino también los costes de amortización de éstos, los seguros, además de neumáticos, reparaciones, mantenimiento, etc., particularmente estos últimos con un importante consumo energético en el proceso de fabricación.

\section{Resultados: hacia un escenario sostenible del Eje Transinsular}

Como hemos señalado, el objetivo último del Eje Transinsular es la integración territorial del Archipiélago a través de la intermodalidad. De este modo, la combinación del transporte terrestre con el marítimo es clave para la movilidad de mercancías entre islas, pero también para el transporte de pasajeros, sobre todo en travesías marítimas de corta duración. El desplazamiento de mercancías rodadas requiere pues un transporte rápido, no solo en fast ferrys - sobre todo para las travesías que superan las 25-30 millas náuticas-, sino también al menos una política de planificación horaria y tarifaria que aminore la fragmentación territorial que, por motivos físicos, es inevitable en las islas y favorezca, por ende, la continuidad territorial más propia de los sistemas continentales.

Pero esta filosofía de transporte, que beneficia sobre todo a los desplazamientos entre las islas más distantes, también conlleva inconvenientes, algunos comprometiendo una política sostenible de transportes, a saber:

1) Incentivo a una movilidad mayor y que incluso podría traducirse en hipermovilidad, no enteramente necesaria o incluso no recomendable, pues habría que incentivar las producciones propias dentro de cada conjunto insular. A su vez, ello comprometería aún más los principios que han inspirado el Protocolo de Kyoto, además de una dependencia energética mayor del exterior. Igualmente, el objetivo 20/20/20 de la Unión Europea no se cumpliría (Eurostat, 
2015), pues la navegación en fast ferry, como hemos demostrado, no es la más sostenible para las Islas desde el punto de vista energético.

2) El Eje Transinsular puede conllevar mayores desequilibrios territoriales dentro de cada isla, al potenciar solo la red viaria que sirve de soporte para las conexiones interinsulares.

Pero para una conexión fluida entre las Islas, habría que incrementar ostensiblemente las frecuencias marítimas -con el inconveniente energético comentado-, ya que para el éxito del Eje Transinsular, no es admisible que una unidad de tráfico permanezca en espera en un puerto más de 60-90 minutos, pues entonces es imposible que ésta pueda alcanzar el otro extremo del Archipiélago tal y como preconiza dicha política y, además, retornar en la misma jornada.

Aun así, es escasamente improbable y entre las islas más alejadas, que una mercancía rodada con su cabeza tractora, pueda cumplir el ciclo de ida y vuelta en un día, por lo que al menos habría que potenciar los trayectos de ida y vuelta entre las cuatro islas centrales entre sí (Tenerife, Gran Canaria, Fuerteventura y La Gomera) o entre las islas periféricas orientales y occidentales con las dos islas centrales de Tenerife y Gran Canaria. Sin embargo, ello tampoco ocurre en la actualidad debido sobre todo a la mala planificación horaria en algunas travesías como Morro Jable-Las Palmas de Gran Canaria e incluso también Santa Cruz de Tenerife-Agaete, en especial para las mercancías procedentes de las islas más occidentales, con tiempos de espera absolutamente inadmisibles.

Por su parte, la política tarifaria actual, al no incentivar de manera contundente la utilización de varias travesías, incrementa de forma notable los costes del desplazamiento -entre un 35 y un 50 \% según hemos comentado- en relación con la misma distancia en territorio continental, hecho que también constituye una asignatura pendiente para la potenciación del Eje Transinsular. En suma, el cambio de política tarifaria por parte de las navieras, obteniendo más tráfico por consiguiente, conjuntamente, y en cualquier caso, con un sistema más racional de subvenciones, contribuiría a paliar las actuales limitaciones imputables a la accesibilidad económica y, por ende, a obtener los objetivos del Eje Transinsular.

\section{Conclusiones}

El Eje Transinsular de Infraestructuras y Transportes, como subsidiario de las Redes Transeuropeas de Transporte, es una política impulsada por el Gobierno de Canarias con el objeto de contribuir a la integración territorial del Archipiélago. Partiendo de la base de la lejanía y fragmentación territorial que soportan las Islas, los sistemas portuarios, aeroportuarios, además de la red viaria que conecta con éstos, se forjan como los pilares de la mentada cohesión territorial. No obstante, estas infraestructuras necesitan de una óptima accesibilidad de los medios de transporte, por lo que el análisis de las infraestructuras por un lado y los medios de transporte por otro, son las piezas claves 
de este trabajo para realizar el diagnóstico del citado Eje Transinsular, a la vez que evaluar su viabilidad futura.

El presente caso de estudio solo analiza la intermodalidad del transporte marítimo con el terrestre, en especial la filosofía que potencia el Eje Transinsular, en el que una mercancía rodada pueda cruzar el Archipiélago de un extremo al otro en una misma jornada, incluso permitiendo a la cabeza tractora regresar a la isla de origen en el mismo día. Para ello, hemos procedido a aplicar una metodología de análisis de la accesibilidad, en el que además de evaluar el papel de las infraestructuras, nos centramos en los medios de transporte, en especial un estudio de accesibilidad horaria y tarifaria, identificando más inconvenientes desde este último punto de vista para la potenciación del Eje Transinsular, que los que ofrece la actual infraestructura de transportes.

En efecto, el Eje Transinsular necesita de fast ferry en casi todas las travesías para que se cumpla la máxima de que una mercancía rodada pueda cruzar el Archipiélago en una misma jornada, con las implicaciones de mayor consumo energético que ello conlleva como hemos demostrado. También es necesario mejorar ostensiblemente los horarios -incrementando las frecuencias o simplemente modificándolos en algunas líneas-, al tiempo que las tarifas, al no incentivar la utilización de dos o más travesías en la misma jornada, detrae una parte significativa de la demanda potencial. De cualquier manera, la actual planificación horaria no permite siquiera el round trip entre las cuatro islas centrales (La Gomera, Tenerife, Gran Canaria y Fuerteventura), por lo que el Eje Transinsular seguirá siendo una quimera mientras los horarios, como mínimo, no permitan la mentada cohesión territorial.

En suma, la metodología aplicada en este trabajo pretende dar las pautas necesarias para que otros espacios -especialmente insulares-, implementen un transporte más sostenible e integrado acorde a las tendencias que marca la Unión Europea en su Libro Blanco (Comisión Europea, 2006).

Agradecimientos: Este trabajo es fruto de los resultados parciales de un proyecto titulado: "Global South. Puertos y desarrollo económico y social en el Atlántico meridional" dentro del Programa Estatal de Investigación, Desarrollo e Innovación orientada a los Retos de la Sociedad en su convocatoria de 2015: HAR2015-64044R (MINECO/FEDER), y del que el autor de este trabajo es uno de los investigadores principales.

Declaración responsable: El autor declara que no existe ningún conflicto de interés en relación a la publicación de este artículo. 


\section{Bibliografía}

Benenson, I., Martens, K., Rofé, Y., \& Kwartler, A. (2011). Public transport versus private car GISbased estimation of accessibility applied to the Tel Aviv metropolitan area. Annals of Regional Science, 47(3), 499-515.

Bowen, J. (2000). Airline hubs in Southeast Asia: national economic development and nodal accesibility. Journal of Transport Geography, 8(1), 25-41.

Brookfield, H. C. (1980). The transport factor in island development. In R. T. Shand, The Island States of the Pacific and Indian Oceans: Anatomy of Development. Development Studies Centre Monograph (pp. 201-238). Canberra: Australian National University.

Button, K. J., \& Taylor, S. (2000). International air transportation and economic development. Journal of Air Transport Management, 6(4), 209-222.

Chang, J. S. (2010). Assessing travel time reliability in transport appraisal. Journal of Transport Geography, 18(3), 419-425.

Chlomoudis, C. I., Pallis, P. L., Papadimitriou, S., \& Tzannatos, E. S. (2007). The liberalisation of maritime transport and the island regions in EU. Evidence from Greece. European Transport. 37, $1-15$.

Chowdhury, S. (2015). The effects of travel time and cost savings on commuters' decision to travel on public transport routes involving transfers. Journal of Transport Geography, 43, 151-159.

Coccossis, H., \& Nijkamp, P. (1995). Overcoming isolation: information and transportation networks in development strategies for peripheral areas. Berlin: Springer.

Comisión Europea (2001). La política europea de transportes de cara a 2010: la hora de la verdad. Luxemburgo: Comisión de las Comunidades Europeas.

Comisión Europea (2005). Trans-european transport network. Ten-t priority axes and projects 2005. Luxemburgo: Comisión de las Comunidades Europeas.

Comisión Europea (2006). Por una Europa en movimiento. Movilidad sostenible para nuestro continente. Luxemburgo: Comisión de las Comunidades Europeas.

Comisión Europea (2011a). Conectar Europa: la nueva red principal de transportes de la UE (MEMO/11/706). Retrieved

from http://web.archive.org/web/20120219040506/http://europa.eu/rapid/pressReleasesAc tion. do ?reference $=M E M O / 11 / 706 \&$ format $=H T M L \& a g e d=0 \&$ language $=E S \&$ guilanguage $=e n$

Comisión Europea (2011b). White Paper on transport. Luxemburgo: Comisión de las Comunidades Europeas. 
Cross, M., \& Nutley, S. (1999). Insularity and accessibility: the small island communities of Western Ireland. Journal of Rural Studies, 15(3), 317-330.

Dijst, M. (2000). Compact urban policies in Randstat Holland. In G. de Roo, \& D. Miller (Eds.), Compact cities and sustainable urban development. A critical assessment of policies and plans from an international perspective (pp. 135-161). Aldershot: Ashgate.

Escudero, A., Muñuzuri, J., Guadix, J., \& Arango, C. (2013). Dynamic approach to solve the daily drayage problem with transit time uncertainty. Computers in industry, 64(2), 165-175.

EURISLES (1996). Systems of transport in the islands. Paris: L'Harmattan.

EUROSTAT (2015). Smarter, greener, more inclusive? Indicators to support the Europe 2020 strategy. Luxemburgo: Comisión de las Comunidades Europeas.

Farrington, J. H. (2007). The new narrative of accessibility: its potential contribution to discourses in (transport) geography. Journal of Transport Geography, 15, 319-330.

Ferrari, C., Parolab, F., \& Gattorna, E. (2011). Measuring the quality of port hinterland accessibility: The Ligurian case. Transport Policy, 18(2), 382-391.

Fundación Tomillo (2001). Los costes de ultraperiferia de la economía canaria. Santa Cruz de Tenerife: Consejería de Economía, Hacienda y Comercio.

Gobierno de Canarias (1998a). Libro Blanco de los transportes en Canarias. Las Palmas de Gran Canaria: Consejería de Turismo y Transportes.

Gobierno de Canarias (1998b). Plan Director de Infraestructuras de Canarias. Santa Cruz de Tenerife: Consejería de Obras Públicas, Vivienda y Aguas.

Gobierno de Canarias (2002). Directrices de Ordenación General y del Turismo de Canarias. Documento aprobado inicialmente. Las Palmas de Gran Canaria: Consejería de Política Territorial y Medio Ambiente y Consejería de Turismo y Transportes.

Grubesic, T. H., \& Fangwu, W. (2013). Essential Air Service: a local, geographic market perspective. Journal of Transport Geography, 30, 17-25.

Guihaire, V., \& Haob, J. (2010). Transit network timetabling and vehicle assignment for regulating authorities. Computers \& Industrial Engineering, 59(1), 16-23.

Guillaumin, M. P. (2001). La dimension ultraperipherique de I'Union Europeenne. In J. Chenb, Problématique des régions ultrapériphériques de I'Union européenne (pp. 142-164). Eurisles: Paris.

Hazledine, T., \& Collins, S. (2011). Paying the pilot? The economics of subsidising international air travel to small remote island nations with large diaspora. Journal of Air Transport Management, 17(3), 187-194. 
Hernández Luis, J. Á. (1994). Transporte aéreo, integración territorial y desarrollo socioeconómico en Canarias. Las Palmas de Gran Canaria: Cámara Oficial de Comercio, Industria y Navegación de Las Palmas.

Hernández Luis, J. Á. (2000). Accesibilidad horaria en el transporte interinsular aéreo de Canarias. Revista de Estudios de Construcción y Transportes, 89, 41-47.

Hernández Luis, J. Á. (2002). Temporal accesibility in archipelagos: inter-island shipping in the Canary Islands. Journal of Transport Geography, 10, 231-239.

Hoyle, B. S. (1999). Islands, transport and development. In E. Biagini, \& B. S. Hoyle, B. S. (Eds.), Insularity and development: international perspectives on islands. London: Pinter.

Jain, J., \& Lyons, G. (2008). The gift of travel time. Journal of Transport Geography, 16, 81-89.

Kaakai, F., Hayat, S., El Moudni, A., \& Kapoor, S. (2006). Schedule coordination for a bimodal connection chain into a Multimodal Hub. IFAC Proceedings Volumes, 39(12), 525-530.

Kapros, S., \& Panou, C. (2007). Chapter 10 coastal shipping and intermodality in Greece: The weak link. Research in Transportation Economics, 21, 323-342.

Knowles, R. D. (2006). Transport shaping space: differential collapse in time-space. Journal of Transport Geography, 14(6), 407-425.

Lei, T. L., \& Church, R. L. (2010). Mapping transit-based access: integrating GIS, routes and schedules. International Journal of Geographical Information Science, 24(2), 283-304.

Liu, S., \& Zhu, X. (2004). Accessibility analyst: an integrated GIS tool for accessibility analysis in urban transportation planning. Environment and Planning B: Planning and Design, 31(1), 105-124.

López Lara, E. (1990). Una visión del papel territorial de la oferta de transporte público de pasajeros por carretera en la Comunidad Autónoma andaluza. Fundamentos para su reforma. Estudios Geográficos, 198, 65-81.

Ministerio de Fomento (2005). Plan Estratégico de Infraestructuras y Transporte (PEIT). Madrid: Ministerio de Fomento.

Ministerio de Fomento (2011). Observatorio del transporte intermodal terrestre y marítimo. Madrid: Secretaría de Estado de Transporte.

Morfoulaki, M., Papanikolaou, A., \& Kapros, S. (2012). Intelligent policy recommendations on ports administration: Introducing a business model approach for the evaluation of ports' services. Procedia-Social and Behavioral Sciences, 48, 2012-2021. 
Neutens, T. Delafontainea, M., Schwanenb, T., \& Van De Weghea, N. (2012). The relationship between opening hours and accessibility of public service delivery. Journal of Transport Geography, $25,128-140$.

Niemeier, D. A. (1997). Accessibility: an evaluation using consumer welfare. Transportation, 24(4), $377-396$.

Nutley, S. (1983). Transport policy aprraisal and personal accessibility in rural Wales. Norwich: Geo Books.

Nutley, S. (1998). Rural areas: the accessibility problem. In B. Hoyle, \& R. Knowles (Eds.), Modern Transport Geography (pp. 185-215). Chichester: Wiley.

Nutley, S. (2005). Monitoring rural travel behaviour: a longitudinal study in Northern Ireland 1979_2001. Journal of Transport Geography, 13, 247-263.

Pitsiava-Latinopoulou, M., \& lordanopoulos, P. (2012). Intermodal passengers terminals: Design standards for better level of service. Procedia-Social and Behavioral Sciences, 48, 3297-3306.

Price, L., \& Matthews, B. (2013). Travel time as quality time: parental attitudes to long distance travel with young children. Journal of Transport Geography, 32, 49-55.

Puertos Canarios (2015). Puertos autonómicos canarios. 1985-2015. Las Palmas de Gran Canaria: Puertos Canarios.

Reis, V. (2014). Analysis of mode choice variables in short-distance intermodal freight transport using an agent-based model. Transportation Research Part A: Policy and Practice, 61, 100-120.

Rigas, K. (2009). Boat or airplane? Passengers' perceptions of transport services to islands. The example of the Greek domestic leisure market. Journal of Transport Geography, 17(5), 396-401.

Robenek, T., Maknoona, Y., Azadeha, S., Chenb, J., \& Bierlairea, M. (2016). Passenger centric train timetabling problem. Transportation Research Part B: Methodological, 89, 107-126.

Rodríguez, I. (1989). Accesibilidad de la población en el medio rural: el caso de San Martín de Valdeiglesias. In Actas XI Congreso Nacional de Geografía, vol I, 206-211.

Rutz, W., \& Coull, J. (1996). Inter-island passenger shipping in Indonesia: development of the system: Present characteristics and future requirements. Journal of Transport Geography, 4(4), 275-286.

Tindemans, H. (2005). Spatial analysis and modelling base don activities: a pilot study for Antwerpen and Gent, Belgium. In K. Williams (Ed.), Spatial Planning, urban form and sustainable transport (pp. 88-110). Aldershot: Ashgate. 
Tsekeris, T. (2009). Dynamic analysis of air travel demand in competitive island markets. Journal of Air Transport Management, 15(6), 267-273.

Tzannatos, E. S. (2005). Technical reliability of the Greek coastal passenger fleet. Marine Policy, 29(1), 85-92.

Yamaguchi, K. (2007). Inter-regional air transport accessibility and macro-economic performance in Japan. Transportation Research Part E: Logistics and Transportation Review, 43(3), 247-258.

Xie, x. (2009). An integrated sea-land transportation system model and its theory. Transportation Research Part C: Emerging Technologies, 17(4), 394-411. 